\title{
Интеграция Украины и ЕС в региональной политике: современное состояние и новые возможности
}

\author{
Виктор Цеханович *
}

\begin{abstract}
Streszczenie: Istotą artykułu jest zainteresowanie i dążenie Ukrainy do obecności w różnych instytucjach europejskich w kontekście procesu integracji i stworzenia warunków do osiągnięcia tych celów gospodarczych Ukrainy. Prowadzi to do ustanowienia procesów integracyjnych do UE i determinuje tworzenie celów rozwoju regionalnego na Ukrainie.
\end{abstract}

Słowa kluczowe: innowacje regionalne, międzynarodowa gospodarka regionalna, strategia klastrowa.

\section{Введение}

На сегодняшний день концепция участия Украины в региональной политике ЕС (еврорегионы, трансграничное сотрудничество, различные кластеры), способствует расширению взаимовыгодного сотрудничества в различных отраслях. Это должно способствовать приграничным административным единицам самостоятельно выходить на европейские структуры для получения технической и финансовой помощи для реализации различных региональных проектов, что приведет к европейской интеграции нашего государства. Каждое государство ЕС формирует собственную региональную политику исходя из уровня социально-экономического развития и национальных приоритетов, а на региональном уровне - от потенциала региона, территориальных различий их развития, особенностей региональных проблем, степени децетрализации государственного управления и уровня ав-

* Lugański Państwowy Uniwersytet im. T. Szewczenki, Ukraina. 
тономии регионов. Характерным для региональной политики ЕС является усиление местной инициативы, предоставление преимуществ региональным инвестициям. В итоге целью статьи можно определить инновационные и транснациональные связи регионов Украины с регионами стран ЕС, выявить новые стратегии регионального развития Украины.

1. Изложение основного материала исследования. Целью государственной стратегии регионального развития, должно стать развитие наиболее перспективных регионов, которые формируют конкурентоспособную структуру хозяйства, а также выравнивание уровней социально-экономического развития регионов.

Основой региональной политики Украины при современных экономических обстоятельствах и бюджетных ограничениях должно быть объединение отдельных принципов и стандартов ЕС с выработкой собственных рычагов усиления конкурентоспособности регионов, что приведет к более высокому использованию региональных ресурсов, рабочей силы и инвестиций, а также к инновациям в новые региональные программы между Украиной и ЕС. Для достижения эффективного регионального развития целесообразно сочетать умеренный протекционизм, поддержку отечественного производства со стимулированием свободного рынка.

Инновационная политика должна является составной частью национальной региональной политики ЕС. При этом правительство, как правило дает преимущество инновационным структурам развития.

В контексте инновационной структуры экономики регионов в европейской практике сложились основные формы поддержки инновационных промышленных систем. К таким формам принадлежат прямое финансирование (субсидии, кредиты), которые достигают 50\% издержек на создание новой продукции и технологий (Франция), предоставление кредитов без выплаты процентов (Швеция), целевые дотации на научно-исследовательские работы, создание фондов внедрения инноваций с учетом возможного коммерческого риска (Германия, Франция, Нидерланды) ${ }^{1}$.

Анализируя современную экономическую обстановку, следует отметить, что в числе основной финансовой помощи в рамках региональной политики $\mathrm{EC}$ начиная с 2014 г. наиболее вероятно будут регионы Южной и Восточной Европы. Не исключено, что возобладают и другие подходы к региональной политике ЕС. Тем не менее даже во многих критических публикациях не подвергается сомнению необходимость масштабного наднационального регулирования территориального развития в ЕС с учетом конвергенции и роста конкурентоспособности регионов. Это позволяет предположить, что шаги по повышению эффективности системы региональной политики ЕС,

1 А. Мельник, В. Адамик, Регіональна політика ЄC та України в умовах поглиблення суперечностей глобалізації, «Журнал Європейскої економіки» 2013, № 3. 
которые приняты до конца 2014 г., приведут к упрощению механизмов этой системы и увеличению ее прозрачности, но не выльются в действительно кардинальные преобразования. Однако, как и во многие предыдущие периоды, возможно внедрение в систему региональной политики ЕС отдельных новых подходов ${ }^{2}$.

Программы ЕС характеризуются как секторным, так и географическим подходами. Это позволяет всем европейским регионам претендовать на определенную форму поддержки, при этом сохраняется концентрация ресурсов в наименее развитых регионах. Система совместного финансирования и партнерства укрепляет права собственности. Органы управления, объединяющие широкий спектр интересов, должны покрывать до половины затрат, связанных с конкретными проектами, за счет местных (государственных или частных) источников.

Задачи региональной политики стран-членов ЕС можно разделить на пять групп. Первая группа - страны с развитой экономической системой (Австрия, Франция, Дания). Данные страны не проводят функциональную региональную политику, так как неравномерность развития регионов в них малозначительна. Основное внимание здесь уделяется привлечению инвестиций во внутренние районы с целью улучшения их конкурентоспособности.

Ко второй группе можно отнести страны Скандинавии. Они характеризуются не высокой плотностью населения, обусловленной суровым климатом и удаленностью населенных пунктов друг от друга. Поэтому региональная политика здесь направлена на решение проблем удаленных северных территорий.

К третьей группе - Германия и Италия т.к. они характеризуются большими внутренними различиями между севером и югом (в Италии) и между «старыми» и «новыми» землями (в Германии). Региональная политика в этих странах нацелена на обеспечение экономического роста более слабых регионов.

Четвертая группа - Ирландия, Греция, Португалия и Испания. В данных государствах региональная политика проводится в условиях слабого развития государственной экономики по сравнению с другими странами - членами ЕС. В следствии этому особое внимание уделяется проблемам национального экономического развития, а вопросам регионального развития отводится второстепенная роль.

К пятой группе можно отнести страны Восточной Европы, не так давно присоединившиеся к Европейскому Союзу (Польша, Венгрия, Чехия, Болгария, Словакия). Данные страны проводят активную региональную политику, направленную на устранение региональных диспропорций.

2 А. А. Попов, Становление региональной политики в Словакии и Словении: два пути в зону «евро», «Социум и власть» 2012, № 1, с. 117-121. 
В Европейском Союзе сформировался наиболее доскональный и эффективный организационно-экономический механизм региональной политики. Для улучшения институционального обеспечения развития регионов страны, интенсификации регионального развития и перевода его в русло европейских традиций и стандартов целесообразным является выяснение возможностей использования европейского опыта институционального обеспечения регионального развития в Украине. Институциональное обеспечение регионального развития предполагает создание необходимых условий для функционирования существующих либо построение новых институтов, которые непосредственно привлекаются к процессам координации усилий в сфере разработки, внедрения и мониторинга региональной политики.

Организационно-экономический механизм региональной политики стран-участниц Европейского Союза состоит из системы планирования территориального развития, которая включает две подсистемы: пространственное планирование и планирование регионального развития. Пространственное планирование предусматривает активное участие в решении региональных проблем самих регионов. На государственном уровне осуществляется регламентация работы системы планирования в целом. В соответствующих законодательных актах формулируются приоритеты регионального развития и механизмы их достижения. При этом главная ответственность за разработку долгосрочных планов развития территорий возложена на сами регионы. В системе национального планирования, кроме подсистемы благоустройства территории, функционирует и подсистема планирования регионального развития. Эти подсистемы в разных странах могут существовать как вместе, так и отдельно.

К сожалению, отдельные принципы ЕС, такие как децентрализация и субсидиарность (которые являются основными), не всегда понятны в Украине, поскольку региональные органы власти из-за неопределенности их стату$\mathrm{ca}$, относительно использования местных ресурсов (природных, трудовых и др.) и не имеют для этого достаточных полномочий и средств. Соответственно постепенное уменьшение зависимости регионов от центра будет способствовать повышению эффективному социально-экономическому развитию регионов.

При условиях интеграции мировой экономики государство должно сотрудничать с регионами, как с равными партнерами. Поэтому изучивши опыт ЕС следует внедрить одно из эффективных направлений - стимулирование внутреннего развития регионов на основе использования местных ресурсов. Это приведет в Украине к перераспределению национального дохода - от регионов с благополучной экономической ситуации к депрессивным.

Отличительными признаками этих регионов является потеря накопленного экономического потенциала и значительные размеры вынужденной ми- 
грации населения. В кризисных проблемных регионах увеличение глубины экономического кризиса может привести к катастрофическим социальным и политическим деформациям. В основном депрессивные регионы имеют достаточно высокий уровень накопленного производственного и технического потенциала, развитую промышленную инфраструктуру, квалифицированную рабочую силу, развитую сеть меж- и внутрирегиональних связей.

С учетом приоритетных целей Украины (сближение отношений с ЕC и дальнейшее вступление в экономический союз) важным элементом экономической интеграции является дальнейшее сближение ее региональной политики с целью четкой идентификации места и роли отечественных регионов в европейской мегаконтинентальной модели «Европа регионов», что предусматривает ${ }^{3}$ :

1) административно-территориальную реформу, что даст возможность выделить уровни NUTS-2 (область) и NUTS-3 (районы), что обозначит их европейскую территориальную иерархию. Это даст возможность получение финансовой помощи из структурных фондов ЕС;

2) выполнение европейских механизмов и инструментов регионального развития (инвестиции, субсидии);

3) развитие еврорегионального сотрудничества;

4) создание независимых условий для инновационного развития регионов.

В данном контексте важным является развитие регионального сотрудничества, в сфере еврорегионов и трансграничного сотрудничества, а в условиях новой геополитической ситуации власть должна дать регионам новую миссию в государстве. Непосредственное соседство Украины со странами EC (сухопутное или морское) открывает приграничным областям не только открывает доступ к рынкам и фондам EC, но и дает возможность взять на себя роль «юго-западного вектора» интеграции Украины в ЕС.

Украина имеет значительный потенциал для развития трансграничного сотрудничества как одного из направлений реализации евроинтеграционных стремлений. В связи с расширением границ ЕС, углубление сотрудничества (трансграничного и еврорегионального) иногда рассматривают как процесс стремления ЕC обеспечить себе максимальную выгоду. Причем отсутствие конкретных гарантий, что до предоставления преференций Украине, рассматривается как недружественные со стороны европейских партнеров. Однако следует понять, что в современных условиях углубление интеграционных тенденций любое государство не избегает влияния данных процессов ${ }^{4}$.

3 Регіональна політика та розвиток місцевого самоврядування, http://old.niss.gov.ua/ book/DOPOVID07/Dopovid-Rozd-6.pdf [дата доступа 5.03.2016].

4 А. В. Балян, Міжрегіональне транскордонне співробітництво України за умов розширення Європейського Союзу (на прикладі прикордонних регіонів України та Угорщини), Ліра, Ужгород 2005, с. 320. 
Особое внимание в данном контексте заслуживает влияние транснационализации экономики (перемещение капитала) на развитие регионов и формирование соответственной региональной политики. Данное влияние на экономику регионов Украины неоднозначное. С одной стороны, размещение капитала рассматривается как ожидание стратегических инвесторов, с другой существуют отличия между частными и транснациональными инвестициями.

Транснационализация экономики регионов должна рассматриваться как процесс вхождения транснациональных капиталов в региональную экономику и создание условий для формирования отечественных интегрированных промышленно-финансовых групп с целью оптимизации структуры экономики регионов и использования их функций для синергетических (методологических принципов) решений разносторонних проблем в региональном развитии. Для достижения обозначенной цели необходимо совершенствовать государственную региональную политику, которая должна содержать блок мероприятий защиты экономической безопасности регионов и гарантировать поддержку отстаивания их интересов в международных регулирующих структурах.

Новые коммерческие транснациональные связи региональных систем, фирм с учетом глобализационных процессов, преобразований в национальной экономике стремятся строить региональную политику, по-новому подходить к традиционной вертикали: экономика предприятия - экономика региона - национальная экономика - мировая экономика; влиять на факторные условия, которые определяют конкурентные преимущества региона, условия взаимодействия отраслей, социально-экономические и политические условия. Именно факторные условия в наибольшей мере определяют конкурентные преимущества региона и ускоряют или тормозят транснациональные процессы.

Как известно, сравнительные (конкурентные) преимущества страны или региона определяются инвестиционным климатом, доступностью ресурсов, развитием технологий.

Процессы транснационализации экономики регионов Украины должны регулироваться средствами региональной политики. Сущность данной политики заключается в мероприятиях, которые осуществляет государство в лице региональных органов власти для получения позитивных синергетических эффектов взаимодействия для формирования инновационно-инвестиционного развития и экономической безопасности регионов. Нежелательное влияние деятельности транснационализации на развитие регионов страны является проблемой конкретной территории, поэтому региональные органы власти должны иметь рычаги влияния на результаты такой деятельности, отображенные в современной концепции государственной региональной политики при условиях формирования законодательной базы регулирования процессов экономики регионов на государственном уровне. 
К сожалению, на сегодняшнем этапе законодательная база Украины в области регионального регулирования устарела т.к. данные законы были приняты в 2001-2005 г. Разработка и использование адаптированного европейского законодательства в Украине на базе стратегии «Европа 2020» приведет, на наш взгляд к новым интеграционным и инвестиционным процессам в приграничных регионах.

Развертывание интеграционных процессов в Европе предопределяет формирование целей региональной интеграции в Украине. Следует отметить, что роль государства в формировании и реализации стратегии регионального развития учитывая, что регулирование должно только увеличиваться. В новой геополитической ситуации, сформированная в мире, только государство как единый политико-правовой субъект способно усилить и реализовать стратегию эффективного развития Украины опираясь при этом на активную позицию регионов.

Каждое направление совместной политики ЕC приобретает региональную окраску. Постоянно растет внимание к применению принципа субсидиарности, а также к взаимодействию разных совместных политик на региональному уровне. В текстах ЕС термин «региональная политика» все чаще заменяют на термин «политика сплочения», что означает переплетение региональной и социальной политики, которые уже не рассматриваются отдельно. Политика сплочения предусматривает одновременное объединение как по горизонтали - между регионами, так и по вертикали - между прослойками общества (социальная политика) ${ }^{5}$.

Расширение функций регионов (как это, например, сделано в Польше) в реализации процессов интеграции может дать положительные результаты при условии оптимизации экономических связей между самими регионами, усиление роли государства в обеспечении политической и экономической безопасности.

Благодаря этим функциям многие воеводства Польши обеспечили себе развитие украино-польских трансграничных регионов, реализацию совместных программ, концепций и стратегий. Среди них следует выделить стратегию трансграничного сотрудничества Люблинского воеводства (Польша), Волынской, Львовской (Украина) и Брестской областей (Республика Беларусь) на 2014-2020 г. в рамках еврорегиона «Буг». Основною целью стратегии является определение направлений данного еврорегиона в различных сферах деятельности: экономической, гуманитарной сфере, охране окружающей среды и т.д.

Сопоставление польско-украинской стратегии трансграничного сотрудничества до 2020 г. со стратегиями развития регионов в данных сферах,

5 Regional policy: introduction, http://europa.eu.int/scadplus/leg/en/lvb/ g24000.htm4 [дата доступа 5.03.2016]. 
к сожалению, не предусматривает конкуренцию данных регионов в данных сферах деятельности. Это должно привести к разработке и созданию новой стратегии развития после 2020 г.

Поэтому и происходит трансформация целей и сущностей региональной политики. Она направляется на формирование новой, активной роли регионов в развитии ЕС. В условиях глобализации регионы начинают отличаться между собой уже не только по социально-экономическим критериям, а и по глобальным критериям - уровнем включения в глобальные процессы. Развивается взаимосвязь между региональными и глобальными партнерами на субрегиональном уровне, а не с государствами. Тем самым формируется новый принцип территориальности без привычного разделения на «центр» и «периферию».

По мнению британского специалиста М. Китинга, формируются важные различия в отношениях между регионами, глобальным рынком, международными режимами и государством в традиционных и глобализационных формах территориального управления. В традиционных формах они опосредованы государством. Регионы здесь служат политической опорой государств и правительств и представлены в государственной политике. Вместо этого, государство предоставляет регионам покровительство и субсидии. Эти отношения нарушаются глобализацией, европейской интеграцией и развитием рынка. Регионы становятся активными составляющими пространства построения новой политики и самостоятельными участниками глобальной политики. Государство теряет свою монополию посредника и способность контролировать собственное экономическое пространство, в то время как у регионов развиваются прямые связи с международными режимами и глобальным рынком. Положение регионов на международном рынке теперь зависит не от политических факторов, а от их конкурентных преимуществ и умения эффективно их использовать ${ }^{6}$.

Одним из важных составляющих регионального роста в современной европейской региональной политике определены кластеры. Как говорится в Стратегии «Европа-2020», кластеры являются важным инструментом для улучшения бизнес-среды, особенно для малых и средних предприятий; они четко выделены в рамках флагманской инициативы «Промышленная политика эпохи глобализации». Кластерные инициативы могут стать мостом к современной промышленной политики и облегчить переход к региональной конкурентоспособности, основанной на модернизации традиционной хозяйственной деятельности за счет инноваций, в частности путем содействия появлении новых товаров, работ и услуг, которые являются конкурентоспособными на мировом рынке.

6 М. Китинг, Новый регионализм в Западной Европе, «Логос» 2003, №6, с. 85-86. 
Кластеры являются важным компонентом умной стратегии региональной специализации, поскольку они предоставляют возможность управленцам упорядочивать различные пути для достижения цели стимулирования экономического роста за счет инноваций. Кластерные инициативы делают возможным решение бизнес-потребностей в их совокупности и обеспечения экономически эффективным способом достижения целей на основе государственно-частного партнерства.

Кроме того, кластеры создают плодотворное сочетание предпринимательской инициативы и потенциала и делают вклад в построение экономики знаний в соответствии с целями Стратегии «Европа-2020». Известно, что региональная политика Европы в то же время демонстрирует солидарность $\mathrm{EC} \mathrm{c} \mathrm{менее} \mathrm{развитыми} \mathrm{странами} \mathrm{и} \mathrm{регионами,} \mathrm{концентрируя} \mathrm{средства} \mathrm{в} \mathrm{тех}$ отраслях и секторах, где они могут дать наибольший эффект. Эта политика направлена на сокращение экономических, социальных и территориальных различий, которые до сих пор существуют между регионами Европы.

Формируя стратегии регионального развития, реализуя меры региональной политики следует иметь четко сформулированные цели развития регионов. Такими целями могут выступить региональная интеграция, межрегиональное сотрудничество на международной арене, особенно в контексте европейской интеграции Украины. В контексте региональной интеграции главной целью выступает рациональное развитие региона, которое происходит на полном использовании их территории. Также главной целью должны выступить максимизация позитивных эффектов интеграции и уменьшение ее негативных последствий. Достижение этой цели будет происходить через использование возможностей в сфере международного регионального сотрудничества, подготовки субъектов хозяйствования и государственных институтов к членству в ЕС.

Соединение системного влияния внутренних и внешних рисков по диспропорции регионального развития, которые приобрели хронический характер, ставит перед Украиной вызовы и стратегические задания по разработке и внедрению новой государственной региональной структурной политики, которая по моему мнению должна быть внедрена после 2020 г. Это связано с тем, что в большинстве регионов Украины уже разработаны данные программы.

Новое качество данных программ предусматривает:

1) мобилизацию и использование ресурсов на нужды увеличения потенциала развития и предоставление стимулов к экономическому росту;

2) создание стимулов к формированию на региональном уровне экономических «точек роста» и усиление их взаимосвязей с периферией;

7 М. О. Кушнір, Сучасні стратегічні орієнтири європейськой регіональної политики, http://sp.niss.gov.ua/content/articles/files/25-1436194571.pdf [дата доступа 5.03.2016]. 
3) создание на региональном уровне эффективных хозяйственных структур, ориентированных на увеличение использования регионального экономического потенциала (региональных и межрегиональных кластеров, индустриальных парков) как основы инновационно-инвестиционных структурных изменений;

4) изменение инвестиционного климата в регионах, что приведет к формированию развитой инфраструктуры.

Новая государственная региональная политика Украины учитывая опыт ЕС должна быть ориентирована на совершенствование отношений «центр-регион», максимальное содействие освоение и использование собственного экономического потенциала регионов и активизации их саморазвития, устранение существенных диспропорций регионального развития, улучшение его институционального развития, повышения уровня сближения региональных подсистем.

Региональная экономическая политика должна создаваться для сравнительных преимуществ в регионах для лидирующих компаний, которые стремятся реализовать сравнительные преимущества путем приближения к крупнейшим потенциальным рынкам, концентрации в пространстве экономической активности, и инновациям. Таким образом будут возникать «ядра», в которые будут стекаться финансовые капиталы и высокопрофессиональные кадры, способные обеспечить производство на современном уровне.

\section{Заключение}

Исходя из вышесказанного, можно сделать вывод, что ЕС очень ярко характеризует подходы к формированию направлений региональной политики, которые показывают полноценную интеграцию.

Инновационность подходов к региональному развитию в Украине должны основываться на использовании катализаторов регионального развития, мотивации регионов к саморазвитию, трансформации сфер экономической активности, создание кластерных зон развития.

Применение инновационных подходов к региональному развитию должно быть направлено на усиление на региональном уровне внутренней мотивации к социально-экономическому росту, создание на региональном уровне конкурентоспособных структур, ориентирование на использование местных ресурсов, формирование на региональном уровне и еврорегиональном уровне конкурентоспособных производств, создание кластеров. 


\title{
Библиография
}

Балян А. В., Міжрегіональне транскордонне співробітництво України за умов розширення Європейського Союзу (на прикладі прикордонних регіонів України та Угорщини), Ліра, Ужгород 2005, с. 320.

Китинг М., Новый регионализм в Западной Европе, «Логос» 2003, № 6, с. 85-86.

Кушнір М. О., Сучасні стратегічні орієнтири європейськой регіональної политики, http://sp.niss.gov.ua/content/articles/files/25-1436194571.pdf

Мельник А., Адамик В., Регіональна політика ЄС та України в умовах поглиблення суперечностей глобалізації, «Журнал Європейскої економіки» 2013, № 3.

Попов А. А., Становление региональной политики в Словакии и Словении: два пути в зону «евро», «Социум и власть» 2012, № 1, с. 117-121.

Регіональна політика та розвиток місиевого самоврядування, http://old.niss. gov.ua/book/DOPOVID07/Dopovid-Rozd-6.pdf [дата доступа 5.03.2016].

Regional policy: introduction, http://europa.eu.int/scadplus/leg/en/lvb/g24000.htm4

\section{Integration of Ukraine and the EU in regional policy: the current state and new opportunities}

\begin{abstract}
Interest and aspiration of Ukraine to various European institutions in the conditions of integration process and creation of preconditions in the state to achievement of these goals. This leads to the establishment of integration processes in the EU and predetermines the formation of the goals of regional development in Ukraine.
\end{abstract}

Keywords: regional innovations, transnational regional economy, regional strategy. 